\title{
On rhetorical patterns in ESL writing and teachers' expectation for the patterns
}

\author{
Bin Lei \\ College of Foreign Language, China Three Gorges University, Yichang City, Hubei Province, China

\section{Email address:} \\ 25866018@qq.com \\ To cite this article: \\ Bin Lei. On Rhetorical Patterns in ESL Writing and Teachers' Expectation for the Patterns. Education Journal. \\ Vol. 3, No. 4, 2014, pp. 235-238. doi: 10.11648/j.edu.20140304.15
}

\begin{abstract}
This paper is organized into three main sections. In the first section, theories and related research on rhetorical patterns are reviewed. The second section analyzes and discusses the rhetorical patterns demonstrated in the essays of ESL learners in China and Canada. The paper is ended with a third section that discusses the implications of this research for the future studies and the teaching of ESL writing.
\end{abstract}

Keywords: Rhetorical Patterns ESL Learners ESL Writing

\section{Introduction}

In 1996 Xiao-ming $\mathrm{Li}$ published his book "Good Writing" in Cross-cultural Context that gave an ethnographical description of teachers' expectation of good writing in China and America. The book convinced us that the "differences in the structure and the style of the written compositions were dependent on the rhetorical traditions of the society" (Li vii), and expert teachers, as the authorities of the traditions, could have "mold[ed] the structure and the style of a whole generation of students" (vii). It is almost two decades since $\mathrm{Li}$ conducted the research, and when it comes to a new generation of ESL teachers and students, the questions arise: How are the students writing now? What are the expectations of the teachers in the new century? In China, since the beginning of this century there have been tremendous changes in every aspect of people's life, and English learning and teaching, with the increasing international communications between China and western countries, has grown into a national passion. This great enthusiasm in English learning is liable to make great impact on the teaching and learning of the ESL writing. In Canada, an increasing number of immigrants from China make the number of Chinese ESL learners grow in the same rapid way. This research, by catching a glimpse of some writings of Chinese ESL learners in regular classrooms both in China and Canada, is to explore something new about the rhetorical patterns in the ESL writing and teachers' expectation for the patterns.
To achieve this goal, the paper is organized into three main sections. In the first section, theories and related research on rhetorical patterns are reviewed. The second section analyzes and discusses the rhetorical patterns demonstrated in the essays of ESL learners in China and Canada. The paper is ended with a third section that discusses the implications of this research for the future studies and the teaching of ESL writing.

\section{Literature Review}

In 1966 Robert Kaplan, a professor in University of Southern California, published in Language Learning his article "Cultural Thought Patterns in Intercultural Education." In the article Kaplan pointed out one of the difficulties in ESL writing was that "[f]oreign students who ha[d] mastered syntactic structures ha[d] still demonstrated inability to compose adequate themes, term papers, theses, and dissertations" (3). Kaplan owed this difficulty to the differences in the rhetoric of different language systems. He examined and analyzed about six hundred foreign student compositions and consequently identified five types of paragraph development which are shown in the following diagram (Kaplan 15):

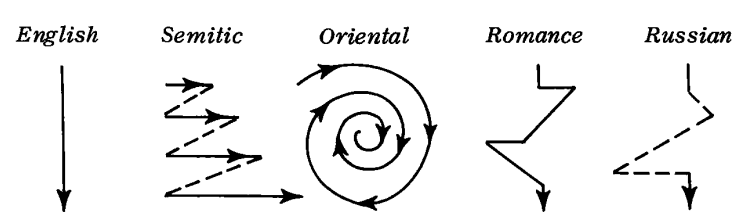


According to Kaplan's contrastive analysis of rhetoric, the paragraph in English culture was developed in a linear way, ideas flowing directly from the beginning to the end, while Chinese native speakers had a circular approach in paragraph development: Some Oriental writing, on the other hand, is marked by what may be called an approach by indirection. In this kind of writing, the development of the paragraph may be said to be "turning and turning in a widening gyre." The circles or gyres turn around the subject and show it from a variety of tangential views, but the subject is never looked at directly. Things are developed in terms of what they are not, rather than in terms of what they are. Again, such a development in a modern English paragraph would strike the English reader as awkward and unnecessarily indirect. (Kaplan 10)

Since Kaplan, more extensive studies have been done on the rhetorical patterns in writing. However, as Kaplan's contrastive rhetoric was criticized for "seeming to privilege the writing of native English speakers" and "to dismiss linguistic and cultural differences in writing among closely related languages" (Connor 494), the directions of contrastive rhetoric research has turned beyond student essays. One direction is to focus on "the writer and the cognitive processes used in the act of writing" (Raimes 408), and the other direction is to study writings in many English for specific purposes situations like Chinese newspapers and sales letters. The results of these studies disagreed with Kaplan's characterization of Chinese texts as circular. For example, in Scollon and Scollon's research, after comparing English language newspapers and Chinese language newspapers, it was found that "there [was] nothing inherent in the linguistic or cognitive structures of either Chinese or English which determine[d] the use of these structures" (107). And in Zhu's study, the findings showed that "all sales letters in the corpus follow[ed] a linear development" (543). However, student essays still appeal to some researchers, and Xiao-ming $\mathrm{Li}$ is one of them. Li did not analyze the rhetorical patterns of the students' papers directly but showed us the picture of the writings through the teachers' eyes. The research revealed the teachers' authoritative role in how their students wrote. It should be worth taking a second look almost two decades after Li's research at the student essays as it is believed that "[r]hetoric, then, is not universal either, but varies from culture to culture and even from time to time within a given Culture. It is affected by canons of taste within a given culture at a given time" (Kaplan 2).

\section{Methodology}

The research targets two groups of ESL learners who are Chinese native speakers. One group is a class of 17 junior English majors in Huangshi Institute of Technology in China, who have learned the basics of English writing and the knowledge of paragraph development. The teacher of this group is Mr. Zhang, who has been teaching English for nearly seven years. Unlike the teachers in Xiao-ming Li's research, who were born and raised in the political turmoil years and educated before China was open to the West in the late 1970s, Mr. Zhang is a new generation. He obtained Bachelor's degree in English Education in 1999 and completed his studies for Master's degree in Linguistics three years later. The other group is a class of eight adults in a private English Language College in Vancouver, Canada, who are taking English writing course part time. The teacher of this group is Ms. Becker, who graduated from UBC with Master's degree in English and currently is an expert on LPI and SAT tests. Both teachers are experienced and have English lessons twice a week, with two periods each time. Although they use different course books, they do emphasize in English writing the basic points like coherence, adequateness and unity. However, there are some differences between the two teachers' writing instruction. First, Mr. Zhang emphasizes more on the differences in rhetorical structures of the two languages. Second, cultural inputs are inevitably distinct since two teachers have their separate educational backgrounds. Third, unlike Ms. Becker, Mr. Zhang sometimes uses both Chinese and English as his lecturing language. The writing task given to the ESL learners in this research was to write an essay according to the question "Do we need honesty?" There was no requirement on the organization and content of the essay, but the learners were expected to finish at least 150 words in 50 minutes. Both teachers were told not to give any suggestion to the learners during the task. After the writing task, the teachers were asked to mark their students' essays. The essays were marked from grade 1 to grade 10 , based on how well the teachers thought the students had developed the paragraphs in their essays. There was a scoring guide based on IELTS composition grading standard including but not limited by the following contents: vocabulary, grammar, sentence pattern, paragraph cohesion and massive structure. Shown in table below are the specific scores of the students from two classes.

Table 1. Composition scores of the students from two classes

\begin{tabular}{lllllllllll}
\hline $\begin{array}{l}\text { score } \\
\text { class } \ \text { number }\end{array}$ & $\mathbf{1}$ & $\mathbf{2}$ & $\mathbf{3}$ & $\mathbf{4}$ & $\mathbf{5}$ & $\mathbf{6}$ & $\mathbf{7}$ & $\mathbf{8}$ & $\mathbf{9}$ & $\mathbf{1 0}$ \\
\hline $\begin{array}{l}\text { MR. Zhang } \\
\text { Ms. Becker }\end{array}$ & 0 & 0 & 1 & 2 & 2 & 4 & 3 & 5 & 0 & 0 \\
\hline
\end{tabular}

\section{Results and Discussion}

As "the criteria to determine circularity and linearity are not very well established" (Zhu 544) and to avoid the controversial concepts like "oriental pattern" or "western pattern" in Kaplan's article, the ESL learners' essays in this research are categorized according to the directness of how the learners have approached the given topic in their writing. One is direct approach and the other is indirect approach.

Direct Approach. There are some pieces that are organized in a quite direct way. These essays have an organized structure and are developed logically, with a 
concluding sentence in the end. One example is the essay written by a student in China. Disregarding grammar and idioms, the composition has a strikingly well-organized structure. The first paragraph defines honesty and answers the topic question directly, and in the following paragraphs the student elaborates in three points the importance of being honest. And it ends with the concluding sentence. It is marked grade 8 by Mr. Zhang. Another example from China's classroom is the essay that starts with a definition of honesty in the first paragraph, discusses the benefit of being honest in the second paragraph, in the third paragraph supports the argument with the counterevidence, revealing the dishonesty and its negative effects on the society, and finally makes a conclusion that we do need honesty. This essay is marked grade 8 as well. In Ms. Becker's class in Vancouver, one of the essays which have received good grade is a little different from the prior examples in China. The essay is not organized in the same point-by-point way, but it is quite coherent and compact as it is fully developed, ideas building one upon the next through to a conclusion. It is marked grade 10 by Ms. Becker. Obviously, the paragraph development in these three essays agrees with what Kaplan described as linear pattern in English writing. It is noticed that the learners in Mr. Zhang's class seem to have a general awareness of the overall structure of their essays. Even some students who show low English proficiency are trying to make their essays well organized. This may be attributed to the high expectation of the Chinese teachers on the organization of the writing. It is learned that Mr. Zhang, when teaching his students to write, has placed great emphasis on how different the paragraphs are developed in Chinese culture and English culture.

Indirect Approach. A few other students argue about the topic in a rather indirect manner. Their essays demonstrate the structure resembling Kaplan's oriental pattern of paragraph development. Some of the students are doing well in grammar, spelling and sentence structure, but what they write seems to lack focus. The sentences are not organized logically and the paragraphs are not developed in the way the previous examples do. Some essays have not answered the question at all. It discusses something around the topic but not the topic per se. For example, in one of the essays, the first paragraph defines "great person" and mentions a great person must be a good person. The second paragraph discusses how to be a good person and in the last sentence of this paragraph mentions honesty which is important for a good person. In the third paragraph the student argues it is unavoidable to tell lies sometimes. And in the last two paragraphs it is concluded that to be honest is hard and to tell lies is even harder, so being honest is easier. Both Mr. Zhang and Ms. Becker have given lower grade to their students who demonstrated this indirect approach of paragraph development. Nonetheless, it is not safe to conclude that this indirectness shown in the students' essays is a kind of rhetorical pattern of certain language. The students write in this way probably because of their weak English proficiency and their inability to focus on the topic.

However, some other students' essays with indirect approach are given high grade by their teachers. Actually, in these essays the students show neutral attitude towards the topic. Some essays start with a question, but never make a definite answer. For example, in one of the essays the student discusses two different opinions about whether we need honesty: "some people hold the opinion that honesty is an essential quality of our life. . . On the contrary . . . honesty does not always do good to us. . . We need honesty, but not always." This essay, surprisingly, is marked as high grade as 8 by Mr. Zhang. There is a similar example in Ms. Becker's class. The essay starts with a positive attitude toward honesty- "In order to have a successful life, we have to be honest", followed by some reasons, and then the student uses a transition to turn to another direction - "However, being honest is a doubleblade sword", and finally it is concluded that "Generally speaking, honesty is the basic quality for us to have, but also we need a maximum for our kindness." This essay is also marked grade 8 by Ms. Becker.

Another finding in this research is that some students like to use historical stories and authoritative examples in the argument. For example, one student in Mr. Zhang's class, when explaining the importance of honesty, quotes a famous sentence by Confucius: "a person can't live any longer without honesty." Another student uses the story of "The Wolf is Coming" 1 to argue how important it is to be honest and how dangerous it is to be dishonest. One student also uses the story of Lei Feng 2as an example of honest people who are respected. In Xiao-ming Li's research, one of the American teachers, Jane, believed any form of authority would "have the undue consequence of stifling students' authentic 'voices' and nullifying their sense of self." (Li 88) Actually, using the historical authorities to make the argument is one aspect of Chinese culture. From Analects of Confucius to Chairman Mao's Talk, writing is regarded as a vehicle of Tao, "which should govern the mind and the acts of both individuals and the state." (Li 116).

The essays collected in this research can be summed up as follows. First, the papers which are given high grade by the teachers are mostly developed in direct approach. Second, some essays which have indirect paragraph development have also received good grades from the teachers. Third, the rhetorical patterns demonstrated in the

\footnotetext{
${ }^{1}$ According to Wikipedia, "The Boy Who Cried Wolf", also known as "The Shepherd Boy and the Wolf", is a fable attributed to Aesop ("The Boy Who Cried Wolf").

${ }^{2}$ It is told in Wikipedia that Lei Feng $(1940-1962)$ was a soldier of the People's Liberation Army in the People's Republic of China. After his death, Lei was characterized as a selfless and modest person who was devoted to the Communist Party, Chairman Mao Zedong, and the people of China. Lei Feng is a cultural icon symbolizing selflessness, modesty, and dedication, and the youth of the country were indoctrinated to follow his example ("Lei Feng").
} 
essays are more complicated than what Kaplan summarized in his article. As shown in the following table, those essays which are hard to tell which 'camp' they belong to are labeled as 'others'. What needs to be emphasized again here is the pre-set definition of the two terms: direct approach and indirect approach. Direct approach: essays are organized and developed in a quite direct and logic way, with most of the sentences relating to the topic. Indirect approach: the topic is argued about in a rather indirect manner, the structure of which resembles Kaplan's oriental pattern of paragraph development. The sentences are not organized logically and the paragraphs discuss something around the topic but not the topic per se. To make this issue less controversial, peer review was adopted. The collected essays were sent to 10 college English teachers for further assessment about the composition classification and scores. There seemed to be no dissent on the classification, but minor difference on certain scores. The following table shows exactly the students performance in the composition writing developed in both direct and indirect approaches, with scores being classified into three ranges.

Table 2. Students' performance in the writing developed in both approaches.

\begin{tabular}{llll}
\hline Sumber & Range 1 & Range 2 & Range 3 \\
type & $\mathbf{1 - - - 4}$ & $\mathbf{5 - - - 7}$ & $\mathbf{8 - - - 1 0}$ \\
\hline direct approach & 1 & 7 & 5 \\
indirect approach & 1 & 4 & 3 \\
others & 2 & 2 & 0 \\
\hline
\end{tabular}

\section{Conclusion}

This research further proves the drawback of Kaplan's model on rhetorical patterns. It should be noted that the language is dynamic and changing, and thus, the findings of the earlier researches on rhetorical patterns may hardly apply to the new situation. Take Chinese language for example: before the New Culture Movement of the mid 1910s what prevailed was traditional Chinese rhetoric, which was hardly influenced by the western doctrines, and after that it was modern Chinese rhetoric, which was to some extent affected by the thoughts from the west; since Chinese economic reform in 1978, with more extensive and deeper communications with the other countries, the Chinese writing has begun to demonstrate more complicated rhetoric, traditional style mixing with the western style. Therefore, it is not reasonable to categorize rhetorical patterns in terms of language system or ethnic group, and it is definitely inappropriate to assume one rhetorical pattern is better than another. Furthermore, for the researchers who study the writing of ESL learners, the rhetorical patterns should be identified and analyzed carefully because there are "multiple factors as possible explanatory variables for L2 writing" (Sasaki and Hirose137), and the pattern demonstrated in one student's writing should not be regarded as the common characteristic of all the students' writing. In the future study, in order to obtain deeper insight on how teachers' expectation can influence the pattern of students' writing, teachers' specific comments on student essays should be examined, and researchers should study diachronically the student essays and teachers' criteria for evaluation to find out the real picture of ESL writing. As for the ESL teachers, teaching students the differences in rhetorical structures of the two languages, as shown in Mr. Zhang's case in this research, would be an effective way to increase the students' awareness of the structure of their writing. From this research, it can be tentatively concluded that the Chinese ESL learners are performing well in the rhetorical patterns of their essays as their teachers' high expectation pushes them to become more aware of this aspect of writing.

\section{References}

[1] Connor, Ulla. "New Directions in Contrastive Rhetoric." TESOL Quarterly 36.4, 2002, pp. 493-510.

[2] Graceffo, Antonio. "English is not a Foreign Language." Foreign Policy Journal. 12 Feb. 2009.

[3] Kaplan, Robert B. "Contrastive Rhetoric and the Teaching of Composition." TESOL QUARTERLY 1.4, 1967, pp. 10-16.

[4] “Lei Feng.” Wikipedia. Web. 10 Oct. 2009.

[5] Li, Xiao-ming. "Good Writing" in Cross-cultural Context. Albany: State U of New York P, 1996.

[6] Raimes, Ann.. "Out of the Woods: Emerging Traditions in the Teaching of Writing." TESOL Quarterly 25.3, 1991, pp. 407-430.

[7] Sasaki, Miyuki, and Keiko Hirose. "Explanatory Variables for EFL Students' Expository Writing." Language Learning 46.1,1996, pp. 137-174.

[8] Scollon, R., and S. W. Kirkpatrick Scollon. "Point of View and Citation: Fourteen Chinese and English Versions of the ‘Same' News Story.” 1997, pp. 83-125.

[9] “The Boy Who Cried Wolf.” Wikipedia. Web. 10 Oct. 2009.

[10] Zhu, Y. "An Analysis of Structural Moves in Chinese Sales Text.” 1997. pp. 543-566. 